\title{
Fast and Reliable Identification of Ammonia Phylotypes T1, T2 and T6 Using a Stereomicroscope: Implication for Large-Scale Ecological Surveys and Monitoring Programs
}

\author{
Jean-Charles Pavard ${ }^{1, *(\mathbb{D}}$, Julien Richirt ${ }^{2}$, Lucie Courcot ${ }^{1}$, Pascal Bouchet ${ }^{3}$, Laurent Seuront ${ }^{1,4,5}$ \\ and Vincent M. P. Bouchet ${ }^{1,3}$ (D) \\ 1 Laboratoire d'Océanologie et de Géosciences, Univ. Lille, CNRS, Univ. Littoral Côte d'Opale, UMR 8187, \\ LOG, Station Marine de Wimereux, 62930 Wimereux, France; lucie.courcot@univ-littoral.fr (L.C.); \\ laurent.seuront@seuront.com (L.S.); vincent.bouchet@univ-lille.fr (V.M.P.B.) \\ 2 LPG-BIAF, UMR-CNRS 6112, University of Angers, University of Nantes, 2 Bd Lavoisier, CEDEX, \\ 49045 Angers, France; richirt.julien@gmail.com \\ 3 Union Sportive Saujonnaise Rugby, Rue Yves du Manoir, 17600 Saujon, France; pascal_bouchet@orange.fr \\ 4 Department of Marine Resources and Energy, Tokyo University of Marine Science and Technology, \\ 4-5-7 Konan, Minato-ku, Tokyo 108-8477, Japan \\ 5 Department of Zoology and Entomology, Rhodes University, Grahamstown 6140, South Africa \\ * Correspondence: jcharles.pavard@gmail.com
}

\section{check for} updates

Citation: Pavard, J.-C.; Richirt, J.; Courcot, L.; Bouchet, P.; Seuront, L.; Bouchet, V.M.P. Fast and Reliable Identification of Ammonia Phylotypes T1, T2 and T6 Using a Stereomicroscope: Implication for Large-Scale Ecological Surveys and Monitoring Programs. Water 2021, 13, 3563. https://doi.org/10.3390/ w13243563

Academic Editor: Luisa Bergamin

Received: 26 October 2021

Accepted: 10 December 2021

Published: 13 December 2021

Publisher's Note: MDPI stays neutral with regard to jurisdictional claims in published maps and institutional affiliations.

Copyright: (c) 2021 by the authors. Licensee MDPI, Basel, Switzerland. This article is an open access article distributed under the terms and conditions of the Creative Commons Attribution (CC BY) license (https:// creativecommons.org/licenses/by/ $4.0 /)$.
Abstract: Among benthic foraminifera, the genus Ammonia is characterized by high morphological variability which makes it particularly challenging to recognize using traditional morphology-based taxonomy. Despite the joint efforts made by both molecular and morphological taxonomists, it is still hard to identify different phylotypes based on their morphology. A new method was developed recently to discriminate three NE Atlantic phylotypes of Ammonia (T1, T2, and T6). This method is based on two morphometrical parameters using scanning electron microscope (SEM) images (i.e., the average pore diameter and the elevation of sutures on the spiral side), resulting individuals being correctly assigned to their phylotype in more than $90 \%$ of cases. In this study, we assess the possibility of implementing these criteria using a stereomicroscope. Phylotype assignations by SEM and stereomicroscopic identifications are in accordance for $62.6 \%$ of the scrutinized foraminifera and increase up to $79.5 \%$ when only the phylotype T6 is considered. Though the stereomicroscopic identification of Ammonia phylotypes based on these two morphological parameters needs to be cross-validated using molecular tools, this approach noticeably allows the identification of an individual 3 to 7 times faster than using a SEM. The ratio between accuracy and efficiency, an issue that is also attributable to the use of the rose Bengal staining method, suggests prioritizing the use of stereomicroscope identifications in large foraminiferal surveys. Finally, in the context that Ammonia phylotype T6 potentially being an alien species in Europe, this method will help to quickly identify Ammonia phylotypes; hence contributing to monitor the presence of $\mathrm{T} 6$ in different regions and then, offering interesting research perspectives to assess the timing and/or the progression of the possible invasion.

Keywords: benthic foraminifera; Ammonia; phylotypes; taxonomy; stereomicroscope

\section{Introduction}

Ammonia was probably the first benthic foraminifera genus described [1], even before the creation of the phylum by d'Orbigny in 1826. The genus is characterized by high morphological variability, which has led to the description of numerous species since the 18th century. However, many species' first descriptions and related drawings are lacking details due to the use of past techniques and technologies that were not as precise as modern ones, such as scanning electron microscopy (SEM). In addition, because the genus Ammonia is distributed worldwide, it potentially suffers from an important "synonymy 
syndrome", that is, taxonomists from different regions of the globe presumably described the same species several times with different names [2].

Despite the considerable efforts made by taxonomists to link morphology-based (e.g., morphospecies) and molecular-based (e.g., phylotypes) taxonomy [3-5], the complexity of the taxonomy of Ammonia has not yet been totally disentangled and the genus still suffers from taxonomical uncertainties [2,4]. One of the most exhaustive recent publications recognizes 67 Ammonia and related taxa that can be morphologically discriminated, with possibly 30 or more additional living species uniquely distinguishable by molecular sequencing [2]. It is known that Ammonia can adapt to diverse environments and tolerate a wide range of different stresses such as salinity, organic matter enrichment, hypoxia, or trace metals [6-10]. However, these species may have different optimal requirements in those ranges and reducing taxonomical uncertainties is then crucial for every aspect of biology and ecology of the Ammonia species in order to better define requirements for each species.

The ability to recognize species morphologically is essential since molecular-based methods are still both expensive and/or time-consuming for the identification of single individuals, particularly in the context of large-scale environmental surveys and ecological monitoring that generate many samples. A recent method based on SEM morphometry was proposed to discriminate three Ammonia phylotypes, belonging to Ammonia tepida [11], morphogroup, occurring along the North East Atlantic coasts (phylotypes T1, T2, and T6) without the need for molecular analysis [12]. However, this method involves a series of successive steps, from mounting specimens on a stub for image acquisition to assessing the two morphometric criteria required: the average pore diameter on the penultimate chamber and the elevation of sutures on the spiral side of the test.

In this context, the present study investigated the possibility of discriminating the Ammonia phylotypes T1, T2, and T6 using only a stereomicroscope, following the suggestion of Richirt et al. [12]. We (i) assessed the accuracy of the identification of Ammonia phylotypes $\mathrm{T} 1, \mathrm{~T} 2$, and T6 using a stereomicroscope, and (ii) quantitatively inferred the time needed to identify one Ammonia individual using SEM images and a stereomicroscope. Being able to identify Ammonia phylotypes using only a stereomicroscope would be highly valuable in the context of studies involving large number of samples, such as large-scale ecological surveys, biomonitoring programs, or paleo-reconstruction of past environments relying on precise taxonomy.

\section{Materials and Methods}

\subsection{Sampling Site}

As part of a larger benthic study aiming to define the Gironde Estuary's $\left(45^{\circ} 25^{\prime} 408^{\prime \prime} \mathrm{N}\right.$, $0^{\circ} 51^{\prime} 407^{\prime \prime} \mathrm{W}$, Figure 1) ecological quality status, benthic foraminifera were sampled in intertidal mudflats.

Sediment samples were preserved in ethanol $(70 \%)$ and rose Bengal solution $\left(2 \mathrm{~g} \mathrm{~L}^{-1}\right)$. In the laboratory, samples were sieved through a $63-\mu \mathrm{m}$ mesh and stained individuals were collected. Among the Ammonia tepida-like picked specimens, three-hundred belonging to the less ornamented (i.e., without or with a few ornaments around the sutures, such as beads, grooves, pustules, bosses, or secondary calcite) Ammonia tepida morphogroup (containing phylotypes T1, T2, and T6 following [3]) were randomly selected for the purpose of this study. 


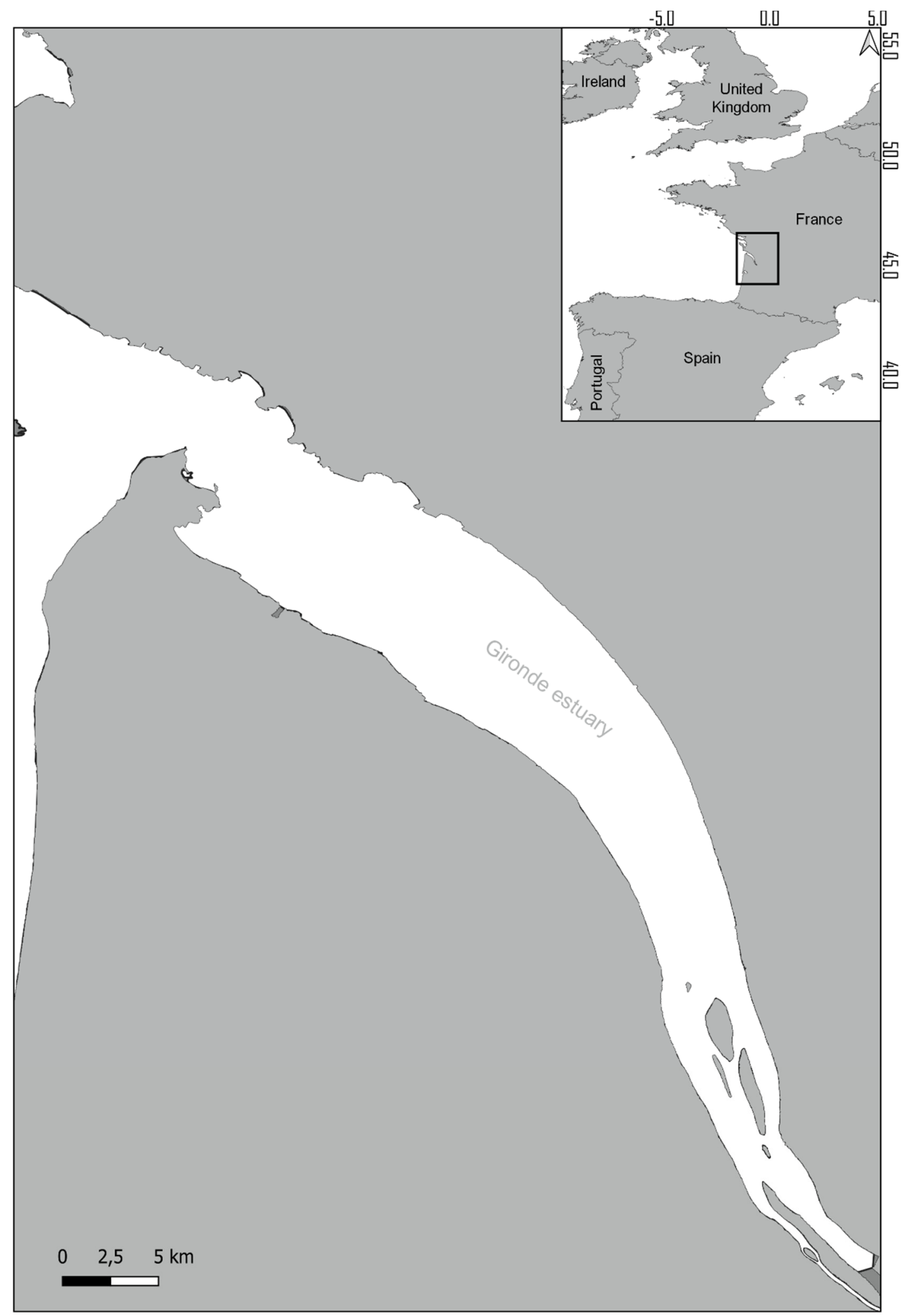

Figure 1. Map of the Gironde Estuary.

\subsection{Ammonia Phylotype Identification}

To ensure an objective assessment of the stereomicroscope and the SEM methods, independent identifications were made by two different investigators. First, specimens were identified with a stereomicroscope using the two criteria proposed by Richirt et al. [5,12]. 
For the first criterium, the elevation of the sutures on the spiral side, i.e., either flush (phylotypes T2 and T6) or raised (phylotype T1), was determined using a source of light external to the stereomicroscope because the raised character of the suture is more apparent when observed with a low-angled light (Figure 2). The second criterium, the average pore diameter, was either considered as small pores when individual pores where not discernible (i.e., phylotype T2, Figure 2b) or as large pores (i.e., phylotype T1 or T6) when individual pores were unambiguously observed (Figure $2 \mathrm{~d}$ ).

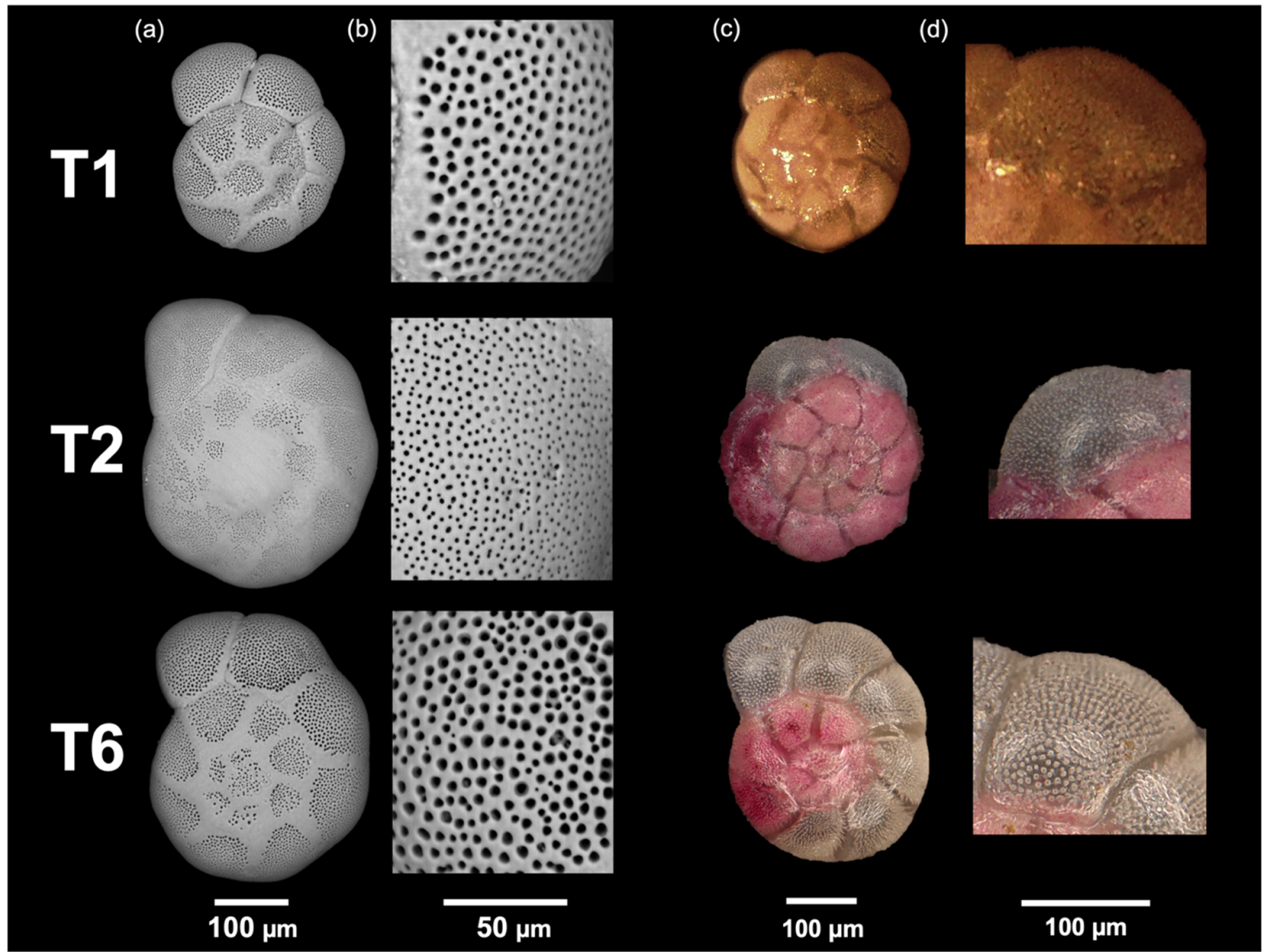

Figure 2. SEM pictures (from Richirt et al. [12]) of (a) general overview of the spiral side, (b) general overview of pores of the penultimate chamber, and stereomicroscope pictures of (c) general overview of the spiral side and (d) general overview of pores of the penultimate chamber of phylotypes T1, T2, and T6. (a,c) represent the suture elevation character ("flush" for T2 and T6, "raised" for T1), (b,d) represent the pore diameter character (small pores for T2, large pores for T1 and T6).

The same specimens were subsequently imaged with a SEM by placing them on 10-mm aluminum stubs (Agar Scientific, Stansted Mountfitchet, UK) with double sticky carbon tabs (Agar Scientific) and sputter coated under argon flow with $\mathrm{Au} / \mathrm{Pd}$ Cressington 108 Auto during 40s and imaged with a SEM LEO (438VP). Two SEM images were taken for each specimen: an overview of the spiral side (for the determination of the elevation of sutures) and a $1000 \times$ magnification of the penultimate chamber on the spiral side (for the average pore diameter measurement). The average pore diameter was measured using the $1000 \times$ magnified SEM image and the ImageJ software [13], following the protocol of Petersen et al. [14]. Individuals were further identified following Richirt et al. [5,12].

Finally, we compared the results provided by the two methods to calculate the rate of correct attributions when using a stereomicroscope compared to the identification 
using SEM images. We further evaluated the time needed to identify one individual with each method.

\section{Results}

\subsection{Identification Time}

Specimen identification using SEM images involves several steps that are described hereafter with the time needed to perform them (Figure 3): (i) mount the specimen on the stub (ca. $10 \mathrm{~s}$ ), (ii) target the specimen on the stub, focus the image and acquire the SEM image (1 to 1:30 $\mathrm{min}$ ), (iii) target the penultimate chamber at a $1000 \times$ magnification, focus the image and acquire the SEM image (1 to $1: 30 \mathrm{~min}$ ), (iv) measure the pores using Image J (1:00 to 2:00 min, depending on the quality of the image), and (v) assess the elevation of the sutures using the overview of the spiral side (10 to $20 \mathrm{~s}$ ). This results in a total SEM identification time ranging between 3:20 and 5:30 min per individual (Figure 3), or between ca. 16.5 and $27.5 \mathrm{~h}$ for 300 individuals. In contrast, a maximum of 30 to $60 \mathrm{~s}$ was needed to assess the suture's elevation and relative pore size, to subsequently assign a phylotype to an individual using a stereomicroscope (Figure 3), or 2.5 to $5 \mathrm{~h}$ for 300 individuals. Therefore, the stereomicroscope method proposed in this study is typically 5.5- to 7-fold faster than using SEM images.

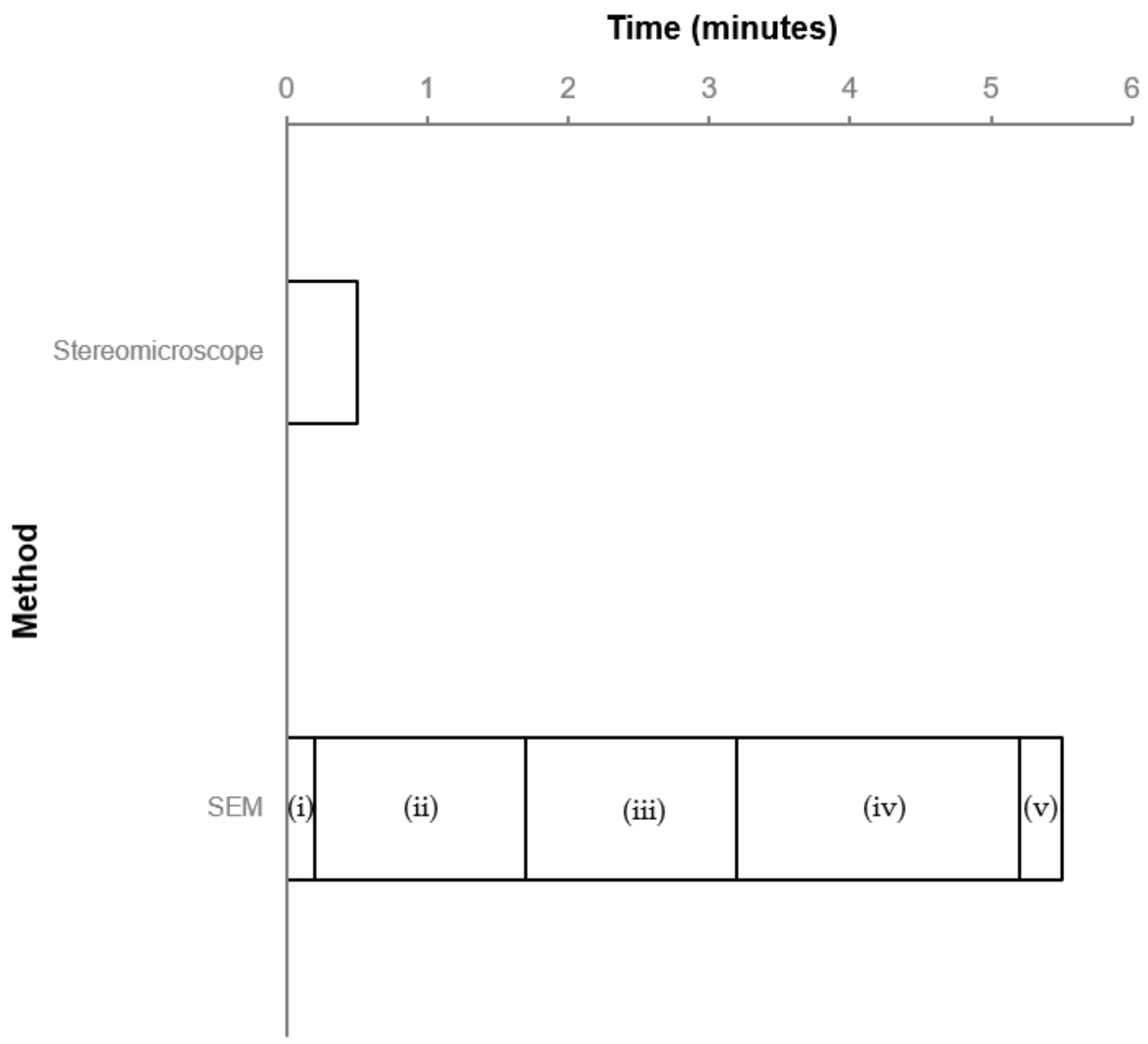

Figure 3. Overview of the time needed to identify the phylotype of a single Ammonia individual using SEM images and using a stereomicroscope. Numbers between brackets represent the different steps of the SEM method that are described in the text. 


\subsection{Correct Assignation Rate between the Two Identification Methods}

Overall, 27 specimens could not be identified by one or the other method because they were too damaged to be analyzed (i.e., broken and/or decalcified/recalcified). Out of the remaining 273 specimens, 171 were assigned to the same phylotype by both methods, while 102 individuals were assigned to a different phylotype (Figure 4, Table S1). This led to a correct attribution rate between stereomicroscopic and SEM images methods of $62.6 \%$. This percentage increased to $79.5 \%$ when considering only the phylotype T6.

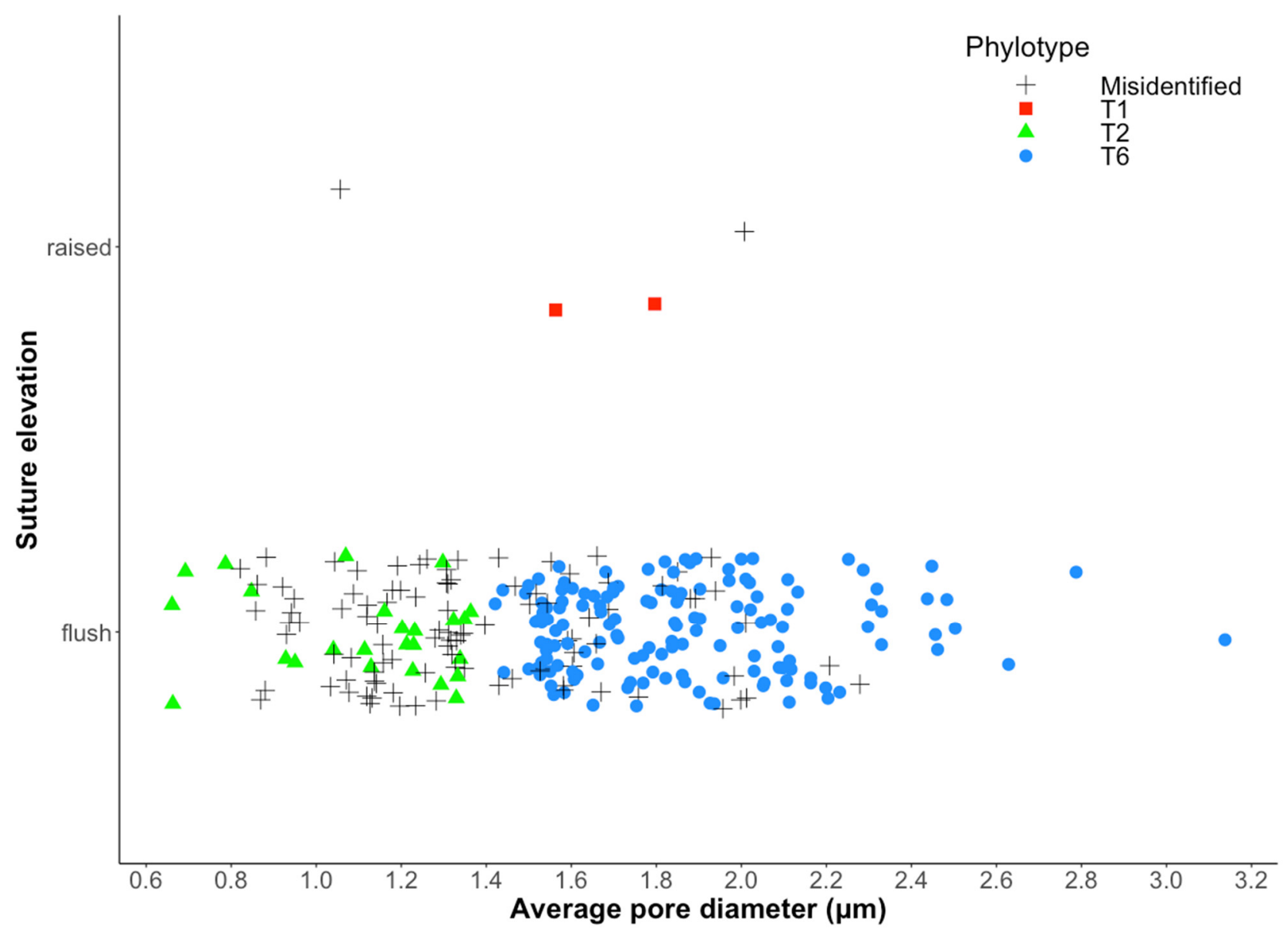

Figure 4. Suture elevation and average pore diameter for the correctly identified Ammonia T1 (red squares), T2 (green triangles), and T6 (blue circles) individuals. When there is a disagreement between SEM and stereomicroscope identifications, individuals are labeled as "misidentified" (black crosses).

Figure 5 shows that most of T2 and T6 individuals' misidentifications are situated under the average pore diameter of $1.42 \mu \mathrm{m}$. Indeed, the two main ranges of mean pore diameter where misidentifications were most observed were from 1.02 to $1.22 \mu \mathrm{m}$ ( 28 individuals) and from 1.22 to $1.42 \mu \mathrm{m}$ ( 24 individuals). We can notice that 17 misidentifications were also observed just above, from 1.42 to $1.62 \mu \mathrm{m}$ of average pore diameter. 


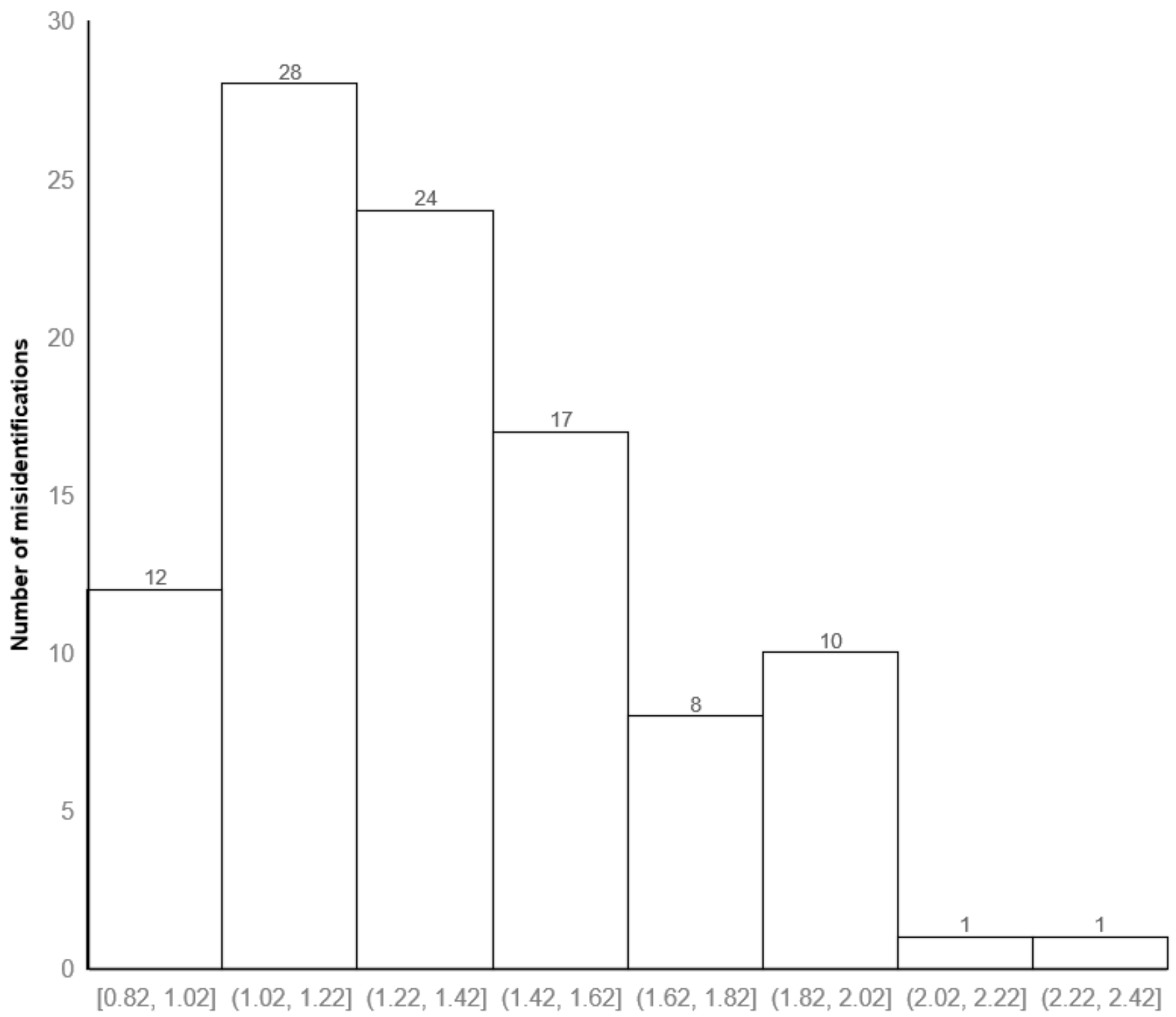

Figure 5. Histogram showing the distribution of misidentified T2 and T6 individuals classified by range of average pore size diameter of $0.20 \mu \mathrm{m}$.

\section{Discussion}

In the present work, we identified Ammonia phylotype T1, T2, and T6 with a stereomicroscope using the two morphological criteria proposed in Richirt et al. [12] initially based on SEM images. Specifically, the rate of correct attribution using a stereomicroscope compared to SEM was $62.6 \%$ when the three phylotypes were considered. Furthermore, correct attribution rates increased to nearly $80 \%$ when only the phylotype T6 was considered. These results suggest that it is easier to recognize T6 than T1 and T2 when only a stereomicroscope is used. This is primarily due to better identification of the larger pores of T6 compared to T2. Similar to Richirt et al. [12], a gap between the average pore diameter of T2 and T6 was observed around $1.4 \mu \mathrm{m}$ (Figure 4). For T6, the average pore diameter ranged between 1.42 and $3.14 \mu \mathrm{m}$; and between 0.66 and $1.40 \mu \mathrm{m}$ for T2. The maximum average pore diameter of $\mathrm{T} 2$ was very close to the minimum average pore diameter of $\mathrm{T} 6$ with a difference of only $0.02 \mu \mathrm{m}$. This explains the difficulty in discriminating between T2 and T6 using their relative pore size with a stereomicroscope instead of measuring their average pore diameter with SEM images. This would be especially true for individuals having an average pore diameter close to the threshold value of $1.4 \mu \mathrm{m}$ [12]. In total, 67 of the misidentified 101 individuals (ca. 66\%) had pore sizes between 1.02 and $1.62 \mu \mathrm{m}$. 
This observation further illustrates the difficulty in discriminating T2 from T6 when their average pore diameters are relatively close.

Despite the fact that identifying Ammonia individuals to phylotypes T1, T2, and T6 was 5.5 to 7 times quicker using a stereomicroscope than using a SEM, the implementation of the stereomicroscope method discussed in this study showed that it is less accurate than using a SEM. Therefore, the issue of the acceptability of the rate of misidentification reported here nevertheless remains an open question. An analogous methodological dilemma between accuracy and efficiency occurs when attempting to identify living and dead foraminifera specimens. Specifically, rose Bengal (RB) staining is less precise than CellTracker Green (CTG) (i.e., 50\% of mean matches and a range of 3-97\% between RB and CTG [15]). Although CTG is more discriminant in identifying living specimens by marking metabolic activity, it is more complex, time-consuming, and expensive to implement, especially for a high number of samples. In the context of large-scale studies, the use of RB has subsequently largely been utilized [16] as it is more convenient and easier to use. Similarly, identifying Ammonia phylotypes T1, T2, and T6 (and by extension all foraminifera species) using only a simple stereomicroscope would be more practical, less time-consuming, and less expensive.

The method implemented here would first, help to not use anymore the formal name of the morphogroup of Ammonia tepida, still often used in large foraminiferal community surveys, and instead, result in the correct identification of numerous individuals of these pseudo-cryptic and distinct Ammonia phylotypes. Secondly, it is compatible with both largescale and long-term ecological studies to be more accurate in term of species composition in the context of biomonitoring programs or paleo-reconstruction of past environments that are generating numerous samples. In a single hour, 120 individuals could be identified using a stereomicroscope, whereas only 17 to 21 individuals could be identified with the SEM method. Quicker accumulation of large datasets coming from these studies could lead to a better understanding of the ecology of Ammonia phylotypes T1, T2, and T6, such as population dynamics, response to environmental parameters, and intra- and interspecific interactions. However, note that in studies aiming to accurately understand the biogeographical distribution and/or ecological requirements of the phylotypes, a more reliable but nonetheless more time-consuming and expensive method of identification (SEM or molecular) may be needed to complement the stereomicroscope method. Finally, SEMs are not necessarily accessible everywhere, making the stereomicroscope the only available method to identify benthic foraminifera species in those situations. Therefore, this method could help to provide data where SEMs are not possible.

In short, like RB is preferred to CTG in large benthic surveys, the relationship between time of identification and correct identification still favors the stereomicroscope in particular cases. For example, this method could be a useful alternative in the investigation of Ammonia sp. T6 as a supposed non-indigenous species in Europe [3,17-19], thought to have replaced the congeneric autochthonous Ammonia sp. T1 and T2 phylotypes [5,20]. It would be quicker to identify the presence of the phylotype T6 in different regions of Europe and then to follow the spreading pattern of T6 both at spatial and time scales utilizing the stereomicroscope method rather than the SEM method.

Supplementary Materials: The following are available online at https:/ / www.mdpi.com/article/10 $.3390 / w 13243563 / s 1$, Table S1: Average pore diameter $(\mu \mathrm{m})$, suture elevation, identifications with SEM, and stereomicroscope approaches for the 273 individuals of this study.

Author Contributions: Conceptualization, V.M.P.B.; methodology, J.-C.P. and J.R.; formal analysis, J.-C.P., J.R. and L.C.; investigation, J.-C.P. and J.R.; resources, J.-C.P., V.M.P.B. and P.B.; data curation, J.-C.P. and J.R.; writing-original draft preparation, J.-C.P.; writing—review and editing, J.-C.P., J.R., L.C., P.B., L.S. and V.M.P.B.; visualization, J.-C.P., J.R. and V.M.P.B.; supervision, V.M.P.B. and L.S.; funding acquisition, V.M.P.B. All authors have read and agreed to the published version of the manuscript. 
Funding: Please add: This research was part of the project Foram-INDIC funded by the Agence de l'Eau Artois-Picardie No. 58183) and the Agence de l'Eau Seine-Normandie (No. 1082222(1)2019). J.-C.P. PhD fellowship received funding supports by the Agence de l'Eau Artois-Picardie (No. 58183) and the University of Lille.

Institutional Review Board Statement: Not applicable.

Informed Consent Statement: Not applicable.

Data Availability Statement: The data presented in this study are available in Table S1.

Acknowledgments: The authors are thankful to Hugues Blanchet, Marie Fouet, Suzie Humbert, Benoit Gouillieux, and Marie Fouet for collecting sediment samples in the Gironde estuary.

Conflicts of Interest: The authors declare no conflict of interest.

\section{References}

1. Brünnich, M.T. Zoologiae Fundamenta. Hafniae Lipsiae Grund. I Dye. 1771.

2. Hayward, B.W.; Holzmann, M.; Pawlowski, J.; Parker, J.H.; Kaushik, T.; Toyofuku, M.S.; Tsuchiya, M. Molecular and Morphological Taxonomy of Living Ammonia and Related Taxa (Foraminifera) and Their Biogeography. Micropaleontology 2021, 67, 109-313.

3. Hayward, B.W.; Holzmann, M.; Grenfell, H.R.; Pawlowski, J.; Triggs, C.M. Morphological Distinction of Molecular Types in Ammonia-towards a Taxonomic Revision of the World's Most Commonly Misidentified Foraminifera. Mar. Micropaleontol. 2004, 50, 237-271. [CrossRef]

4. Holzmann, M.; Pawlowski, J. Taxonomic Relationships in the Genus Ammonia (Foraminifera) Based on Ribosomal DNA Sequences. J. Micropalaeontol. 2000, 19, 11. [CrossRef]

5. Richirt, J.; Schweizer, M.; Mouret, A.; Quinchard, S.; Saad, S.A.; Bouchet, V.M.P.; Wade, C.M.; Jorissen, F.J. Biogeographic Distribution of Three Phylotypes (T1, T2 and T6) of Ammonia (Foraminifera, Rhizaria) around Great Britain: New Insights from Combined Molecular and Morphological Recognition. J. Micropalaeontol. 2021, 40, 61-74. [CrossRef]

6. Alve, E. Benthic Foraminiferal Responses to Estuarine Pollution; a Review. J. Foraminifer. Res. 1995, 25, 190-203. [CrossRef]

7. Bouchet, V.M.P.; Debenay, J.-P.; Sauriau, P.-G.; Radford-Knoery, J.; Soletchnik, P. Effects of Short-Term Environmental Disturbances on Living Benthic Foraminifera during the Pacific Oyster Summer Mortality in the Marennes-Oléron Bay (France). Mar. Environ. Res. 2007, 64, 358-383. [CrossRef] [PubMed]

8. Armynot du Châtelet, E.; Debenay, J.-P.; Soulard, R. Foraminiferal Proxies for Pollution Monitoring in Moderately Polluted Harbors. Environ. Pollut. 2004, 127, 27-40. [CrossRef]

9. Mojtahid, M.; Geslin, E.; Coynel, A.; Gorse, L.; Vella, C.; Davranche, A.; Zozzolo, L.; Blanchet, L.; Bénéteau, E.; Maillet, G. Spatial Distribution of Living (Rose Bengal Stained) Benthic Foraminifera in the Loire Estuary (Western France). J. Sea Res. 2016, 118, 1-16. [CrossRef]

10. Nikulina, A.; Polovodova, I.; Schönfeld, J. Foraminiferal Response to Environmental Changes in Kiel Fjord, SW Baltic Sea. eEarth 2008, 3, 37-49. [CrossRef]

11. Cushman, J.A. Recent Foraminifera from Porto Rico; Carnegie Institution of Washington: Washington, DC, USA, 1926; Volume 342.

12. Richirt, J.; Schweizer, M.; Bouchet, V.M.P.; Mouret, A.; Quinchard, S.; Jorissen, F.J. Morphological Distinction of Three Ammonia Phylotypes Occurring Along European Coasts. J. Foraminifer. Res. 2019, 49, 76-93. [CrossRef]

13. Rueden, C.T.; Schindelin, J.; Hiner, M.C.; De Zonia, B.E.; Walter, A.E.; Arena, E.T.; Eliceiri, K.W. ImageJ2: ImageJ for the next Generation of Scientific Image Data. BMC Bioinform. 2017, 18, 1-26. [CrossRef] [PubMed]

14. Petersen, J.; Riedel, B.; Barras, C.; Pays, O.; Guihéneuf, A.; Mabilleau, G.; Schweizer, M.; Meysman, F.J.R.; Jorissen, F.J. Improved Methodology for Measuring Pore Patterns in the Benthic Foraminiferal Genus Ammonia. Mar. Micropaleontol. 2016, $128,1-13$. [CrossRef]

15. Bernhard, J.M.; Ostermann, D.R.; Williams, D.S.; Blanks, J.K. Comparison of Two Methods to Identify Live Benthic Foraminifera: A Test between Rose Bengal and CellTracker Green with Implications for Stable Isotope Paleoreconstructions. Paleoceanogr. Paleoclimatology 2006, 21, PA4210. [CrossRef]

16. Schönfeld, J.; Alve, E.; Geslin, E.; Jorissen, F.; Korsun, S.; Spezzaferri, S. The FOBIMO (FOraminiferal BIo-MOnitoring) InitiativeTowards a Standardised Protocol for Soft-Bottom Benthic Foraminiferal Monitoring Studies. Mar. Micropaleontol. 2012, 94-95, 1-13. [CrossRef]

17. Schweizer, M.; Polovodova, I.; Nikulina, A.; Schönfeld, J. Molecular Identification of Ammonia and Elphidium Species (Foraminifera, Rotaliida) from the Kiel Fjord (SW Baltic Sea) with RDNA Sequences. Helgol. Mar. Res. 2011, 65, 1-10. [CrossRef]

18. Pawlowski, J.; Holzmann, M. Diversity and Geographic Distribution of Benthic Foraminifera: A Molecular Perspective. Biodivers. Conserv. 2008, 17, 317-328. [CrossRef] 
19. Polovodova, I.; Nikulina, A.; Schönfeld, J.; Dullo, W.-C. Recent Benthic Foraminifera in the Flensburg Fjord (Western Baltic Sea). J. Micropalaeontol. 2009, 28, 131-142. [CrossRef]

20. Bird, C.; Schweizer, M.; Roberts, A.; Austin, W.E.N.; Knudsen, K.L.; Evans, K.M.; Filipsson, H.L.; Sayer, M.D.J.; Geslin, E.; Darling, K.F. The Genetic Diversity, Morphology, Biogeography, and Taxonomic Designations of Ammonia (Foraminifera) in the Northeast Atlantic. Mar. Micropaleontol. 2020, 155, 101726. [CrossRef] 